International Journal of Social Science and Economic Research

ISSN: 2455-8834

Volume:05, Issue:08 "August 2020"

\title{
THE CAUSES AND SOLUTIONS FOR GENDER EQUALITY IN RURAL EDUCATION IN DAI TAM, MY XUYEN DISTRICT SOC TRANG PROVINCE, VIETNAM
}

\author{
Tran Thi Diem Can ${ }^{1}$, Nguyen Van Tron ${ }^{2}$ \\ ${ }^{1}$ MSc., Department of Sociology, School of Social Sciences and Humanities, Can Tho University \\ ${ }^{2} \mathrm{MSc}$, Department of Criminal Law, School of Law, Can Tho University \\ DOI: 10.46609/IJSSER.2020.v05i08.005 URL:https://doi.org/10.46609/IJSSER.2020.v05i08.005
}

\begin{abstract}
The study was conducted to analyze the causes of gender equality in education in My Xuyen district, Soc Trang province, since then, the study proposed several solutions to narrow the gender inequality gap in education at the study area. Research data were collected from 250 households who are having children attending school at all levels. Descriptive statistical methods, frequency analysis, crosstab analysis, Cronbach's Alpha test and Exploratory Factor Analysis (EFA) method were used in the study aiming to analyze the causes affecting gender equality in education. The research results showed that there are four causes affecting education equality, including Social prejudice, Family economic condition, Schooling environment and Individuals.
\end{abstract}

Keywords: Dai Tam, education, gender equality, My Xuyen district, Soc Trang province

\section{Introduction}

In Vietnam, gender-related issues are increasingly concerned by institutions, organizations as well as individuals. It can be seen that this issue is one of the goals of fostering other issues of social development, especially education. It is revealed that gender equality in education has a positive impact on the quality of human resources of the future. However, there are still many issues to be considered in terms of gender equality in education and training. As can be showed that female roles are not considered rightly. For example, in the educational workplace, female teachers are not accepted by many principals due to some troubles related to maternity leave, family responsibility as children, parents and so on affecting teaching, or even, promoting position as well as getting higher degree oppotunities are more reserved than men. In addition, in rural areas until now, people also think that males are easier to achieve high social positions than 


\section{International Journal of Social Science and Economic Research}

ISSN: $2455-8834$

Volume:05, Issue:08 "August 2020"

females so that females are less likely to attend school than men. On average for all developing countries, the literacy rate for females is lower than for males counted for $29 \%$, the average number of years attending the school of females is lower than for males (45\%), and the enrollment rates of the primary, lower secondary and upper secondary levels of females are lower than males like 9\%, 28\% and 49\% respectively[1]. Therefore, promoting gender equality in education is a long-term strategy and it brings effectivenesses only if gender mainstreaming is considered a consistent principle in the educational environment at the individual and organizational levels. In this way, gender equality and gender violence will be really ended.

Gender equality is a matter for males and females to have an equal position and role, to be created conditions and opportunities to promote themselves for the community development, the family and to be enjoyed the same benefits about the achievement of that development [2].

Gender equality is legal equality, opportunity (including equality in work remuneration and access to human capital and other productive resources) and speaking (an ability to influence and contribute to the development process). Gender equality is also the process of overcoming gender inequality between males and females, but not eliminating the natural differences between them through special treatment with females. In order to achieve gender equality in an environment where female's opportunities, conditions and social position are lower than males is special treatments should be given to the priority to females which is the basis of true equality $[3 ; 1]$.

In contrast to gender equality, gender inequality is a different treatment for males and females in terms of opportunities, participation, right access, control and enjoyment of resources. Discrimination between males and females, the idea of male chauvinism can be considered as a big influence on domestic violence against females [4]. Inequality is the inequality between males and females, between groups of males and females in opportunities, access rights to resources, the use and enjoyment of social achievements [5].

Inequality in education means that the learning opportunities of males and females are unfamiliar, the potential development of one gender is more important than the other. Inequality in education is often understood to be an unfair distribution of learning resources (budgets, teachers, technology or facilities, etc.) among different groups in society, making groups have little or no opportunity to receive education and achieve the accomplishments they could have achieved [1;5]. Inequality in education is often attributed to its roots as economic inequality. Of course, it can also be related to social inequality (gender, region, ethnic, language, etc.), but in the real context of Vietnam, the most important is still the difference between rich and poor. The fact that these two things are inseparable [6]. 


\section{International Journal of Social Science and Economic Research}

ISSN: $2455-8834$

Volume:05, Issue:08 "August 2020"

In the world, there are many studies on the issue of gender equality, it is shown that the interest of people on this issue, and this is the leading goal in promoting gender equality, empowering more females. According to UNESCO's Global Education Gender Report 2019, the number of adult illiterate females in middle-income countries has dropped by 42 million in the past 16 years. In the world's poorest countries, it is still important to give females an opportunity to school and this is a successful way due to their safer daily commute. Of the 20 countries with large disparities in the rate of males and females in schools, Guinea, Nigeria and Somalia stand out for their commitment to being closed the gap between the number of males and females attending school [7]. In Korea, a small number of females appointed with long-term contracts in science and technology accounted for $19 \%$ while it was $81 \%$ of males. Not only are they limited to promotion to a higher position, but those with family responsibilities often choose not to continue their career due to limited childcare facilities as well as opportunities for technical development and skills after childbirth [8].

A quarter of people worldwide still believed that higher education is more important for males than females. This ideology is also reinforced in schools. Even textbooks promote this prejudice and ignore females' historical contributions. While most teachers are females, school leaders are often males. Females make up just over a quarter of those registered for technical, manufacturing and construction programs, as well as information and communication technology programs. Such gender prejudices often lead to a permissive attitude - not only socially, but also legally for child marriage, early pregnancy, housework and even sexual force, even at school. At least 117 countries and territories still allow children to marry. Four countries in sub-Saharan Africa prohibit females from returning to school during or after pregnancy. And females children in most countries are more than twice as likely to be involved in household chores than male children. Countries such as Angola, Central African Republic, Djibouti and Mauritania barely mention gender in all of their educational strategies [7].

In Vietnam, gender equality is considered as a matter of special priority by the Party and the State. The Gender Equality Law sets out the goal of creating equal opportunities for males and females in socio-economic development and human resource development, but in reality, inequality still exists. The gender inequality index in Vietnam is 0.337 , ranked 71/195 countries and territories. It is illustrated that Vietnam still faces many challenges in ensuring gender equality between males and females [7]. In education, inequality manifests itself in many aspects, including some specific signs such as the opportunity to participate in the national education system, the difference disparities in educational attainment, male and female qualifications, opportunities for improving professional qualifications. Rigid traditional views, male and female role values are discovered as the underlying causes of gender inequality in Vietnam [1;4]. Females have significantly lower education levels than males. Females tend to focus more on lower secondary education and lower (70.78\% and $60.28 \%$ respectively), and less 


\section{International Journal of Social Science and Economic Research}

ISSN: $2455-8834$

Volume:05, Issue:08 "August 2020"

in the upper secondary and higher groups (29.22\% and 40.33, respectively). Females are often expected to give up higher education to their brothers and tend to drop out of school to take care of their families. In urban areas, investment in education is many times higher than in rural areas, and this investment is increasing by the levels of education from low to high in both areas. Inequality in education is quite common in terms of literacy and education levels among regions, between ethnic minorities and Kinh, urban and rural areas[9;1]. Some causes leading to inequality in rural education are also existing prejudices about the role and position of females in the family and society, due to the thought of "patriarch of males in the family", the thought of "male chauvinist", ...[12;11;10].

It can be seen that gender equality is a very important issue concerned by society in general and scientific research in particular. If the issue of female liberation is the most fundamental in females' struggle, the equality right between males and females is considered the most fundamental content. Researching gender equality in education is necessary work in society today, aiming to find out ways to improve gender equality in education and in society. Therefore, the study of the causes and solutions for Gender Equality in Rural Education in Dai Tam, My Xuyen District, Soc Trang Province is very necessary.

\section{Research methodology}

Qualitative and quantitative methods are used in the study to analyze data. Research secondary data were collected from previous articles, research works, journals, reports related to gender inequality in education. Besides, data were collected from the latest statistical yearbook of the study area to refer the data with research results, preliminary reports, annual reports, and terms of Office of People's Committee, People's Council of Dai Tam Commune and People's Council of My Xuyen District, Soc Trang Province. Primary data were collected from 250 households who are having children attending school at all levels. Descriptive statistical methods, frequency analysis, crosstab analysis and Cronbach's Alpha test, EFA method were used in the study $[13 ; 14]$.

All scales in the study used Likert scale with 5 levels including 01 to 05 according to the degree of agreement as $1=$ strongly disagree; $2=$ disagree; $3=$ normal; $4=$ agree; $5=$ strong agree with factors affecting gender equality in Dai Tam, My Xuyen, Soc Trang.

The study looked at both Vietnamese and foreign research works written on self-study as well as factors affecting gender equality in education in rural areas. Based on the process of analyzing and synthesizing documents, the research proposed a model following the research objectives. The analytical model consists of two main components: gender equality is the dependent variable (Y), family conditions, family orientations, individuals, schooling environment, social prejudice, supportive policy local are independent variables (Xi). 
International Journal of Social Science and Economic Research

ISSN: $2455-8834$

Volume:05, Issue:08 "August 2020"

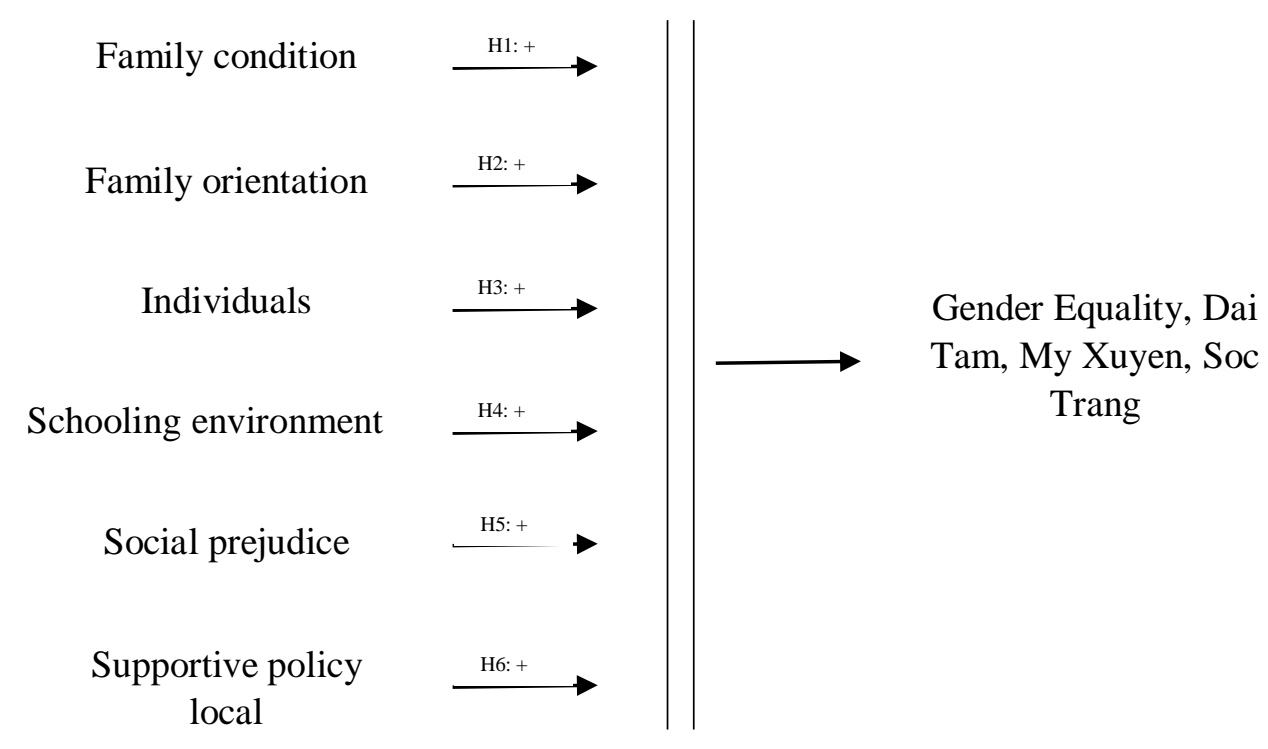

Figure 1. Research model proposed by author

(Source: Surveyed by the author, 2020)

\section{Findings and discussions}

\subsection{The situation of gender equality in education in Dai Tam, My Xuyen, Soc Trang}

The research data were collected from 250 households living in Dai Tam Duc Commune, My Xuyen District, Soc Trang Province because this is one of the commune having large Khmer ethnic population, accounting for more than $86 \%$ of the population of the commune, education issues are more concerned by the authorities and local people than other communes in the district. Besides, there are also Kinh and Hoa ethnic people living alternately, with mainly doing farming and different social classes. The main thing that helps reflect a comprehensive and objective of the research data.

Regarding education in the study site of the time parents spent on teaching children, research results indicated that parents have not spent time teaching children accounted for $36 \%$, and this is consistent with the actual situation as the majority of high school students are boarding-students in the study area. Most students have to study away from home, so parents cannot follow their children's education. The time parents teach their children from 1 to 15 minutes, from 15 to 30 minutes and 30 to 60 minutes, respectively, account for $3.2 \%, 13.6 \%$ and $17.6 \%$.

The following data were collected by a given mark from $1-5$ with convention $1=$ Strongly disagree completely; $2=$ Disagree; $3=$ Neutral; $4=$ Agree; $5=$ Strongly agree for objects surveyed. Then the number in the table is calculated by descriptive method that the meaning of each 
International Journal of Social Science and Economic Research

ISSN: 2455-8834

Volume:05, Issue:08 "August 2020"

average value for scale range (Interval Scale) Value range $=($ Maximum - Minimum $) / \mathrm{n}=(5-1)$ $/ 5=0.8$

\section{The average value}

$1.00-1.80$

$1.81-2.60$

$2.61-3.40$

$3.41-4.20$

$4.21-5.00$

\section{Meaning}

Strongly disagree

Disagree

Neutral

Agree

Strongly agree

Source: Hoang Trong \& Chu Nguyen Mong Ngoc, 2008

Regarding the decision of parents to take their children out of school to earn money with an average value of 3.85 , it is showed that the agreement of the family with this because of difficult circumstances, deprivation, minimum needs to meet family members for food and clothing, so this option is perfectly reasonable for practical conditions. In addition, the average of parents took their children out of school to do housework with an average value of 3.52. It proved that parents agreed to take their children out of school to do housework. Leaving school to do housework will often happen with more females than males since females can do them better and clever than males.

In addition, surveying households' perceptions of knowledge approach and thinking between males and females, they mainly respond that the approach of males is more clear-headed than females. There are different ideas from male and female respondents. Whereas female respondents agreed with the above point of view, they followed the old traditional conception and they are accepted, male respondents disagreed with this view, they believed that the ability to approach the knowledge and thinking of both gender is similarity. It is indicated that females followed views of today's society, and they have been approaching progressive views.

\subsection{Causes of gender equality in education in Dai Tam, My Xuyen, Soc Trang}

Various reasons are leading to inequality in education in rural areas of Dai Tam, My Xuyen district, Soc Trang province. It also depends on various reasons such as family tradition, individuals, parents' income and perceptions of education in the studied area. After surveying 250 households in the study area, there are mainly four causes given as follow:

Firstly, one of the causes affecting gender inequality at the study site is social prejudice, which has an impact on gender inequality in education. It is figured out that most respondents strongly agreed that women do not need to be highly educated, women should not achieve an educational level higher than their husbands with an average value of 4.28 , and respondents also agreed with the view that women are less sensitive than men, with a significance level of 4.07. It can be seen 


\section{International Journal of Social Science and Economic Research}

ISSN: $2455-8834$

Volume:05, Issue:08 "August 2020"

that gender prejudice about education is also widely manifested in society by the lack of clarity of right-and-wrong but unanimously recognized, which has become the basis for forming a gender behavioral pattern. The conditions and learning opportunities of males and females have been significantly affected by this point of view.

Secondly, inequality in education at the study site is also affected by family conditions and circumstances. Different families will have different inequality in education. Especially, respondents agreed with the most frequent issues of relocation with an average value of 4.00. The frequent relocation of parents leading to change the continuous school of their children. The reason has made up affecting children's learning and development. Meanwhile, the educational level of parents did not receive much agreement from the respondents that affect their children going to school with a significance level of 3.76 .

The third reason for the issue is that there are many factors from schooling environment that affect inequality in education in rural areas, especially Dai Tam, My Xuyen district, Soc Trang province. Most respondents strongly agreed on the discrimination between males and females by teachers as well as discrimination between Khmer and Kinh students that contribute to inequality in education, with a significance level of 4.13. In a school environment, teachers have a distinction between students and students, and students are also discriminated against each other because of language differences in the communication process. This is influenced by incorrect prejudice about gender and ethnic minorities. Respondents also agreed with the idea of male and female access to different activities in the school, with a significance level of 3.99.

The final reason for the issue is that individual factors also affect inequality in education such as the awareness and passion of each person. Most respondents strongly agreed that the capacity of thinking and creativity in the learning process is a cause that has a strong impact on gender equality, with a significance level of 4.33. Male students have more creative thinking, more sensitive to issues than females, while female linguistic abilities are better than males. Respondents also agreed with the awareness of men and women in learning, with a significance level of 3.98 .

\subsection{Factors affecting gender equality in education at Dai Tam, My Xuyen, Soc Trang}

Six-factor groups affect the equality in education at the study site, through Cronbach's Alpha test, most Alpha coefficients are greater than 0.6, showing that this scale is acceptable [14]. The result of EFA with tests is guaranteed with the reliability of observed variables (Factor loading> $0.5)$; Test the suitability of the model $(0.5<\mathrm{KMO}=0.827<1)$; Bartlett test of correlation of observed variables $(\mathrm{Sig}=0.001$ and $\mathrm{Sig}<0.05)$; Testing the variance of the model is $80.1 \%$ (Cumulative variance> 50\%). Thereby 35/40 factors are drawn into 06 independent variables. 


\section{International Journal of Social Science and Economic Research}

ISSN: $2455-8834$

Volume:05, Issue:08 "August 2020"

The factor group B1 named local support policy (LP) consists of 12 closely related variables and has a coefficient of load factor of 0.775 to 0.896 . These included Opening more training classes to raise parents' awareness and qualifications (X38); Building quality assurance schools (X39); Developing safety plans for students (X40); Propagating laws on education for local people about gender equality in education (X35); Implementing policies on poverty reduction (X36); Propagating for people about building gender equality in society (X34), Creating jobs for disadvantaged families (X30), Investing in education (X37), Supporting vocational training for families (X31), Transfering the science and technology to improve crop productivity (X32), Encouraging families to send their children to school (X33), Encourage the construction of local schools, policies for the poor and ethnic people (X29).

The B2 factor group is named family condition (FC), which consists of 6 observed variables that are closely related and have a coefficient of load factor 0.810 and 0.943 , including, Unstable economy and jobs (X4); Low household income (X1); The poor living conditions (X2); Families with many children (X3); Very often relocation (X5), the low education level of parents (X6).

The B3 factor group named social prejudice (SP), consists of 5 observed variables that are closely related to each other and have a load factor of 0.693 to 0.959 , including, the disparity of thinking and creativity between males and females (X21); Females only taking on housework (X19); The disparity of Educational level between females and their husbands (X20); Differences on the sensitivity of males and females (X22). The disparity of social position between males and females (X18).

The B4 factor group named school environment (SE) consists of 5 observed variables that are closely related, and have a load factor of 0.719 to 0.850 ., including, Less experienced teachers to balance thinking and creating opportunities for both males and females (X25); Lack of learning and teaching materials (X26); Lack of entertainment environment for gender development (X28); Opportunities to access school activities between males and females (X24), Discrimination against Khmer and Kinh students (X27).

The B5 factor group is named family orientation (FO), which consists of 4 observed variables that are closely related and have a load factor of 0.792 to 0.884 , including, Understanding of parents with children's interests (X8); Respecting children's career decisions (X10); Freedom right of children in career opportunity (X7); Various path to success in children (X9).

The B6 factor group named as individuals (IN) consists of 3 observed variables that are closely related and have a load factor of 0.789 to 0.812 . These included Personal passions (X14); Capability of thinking and creativity (X15); Ability to integrate into the community (X16). 
International Journal of Social Science and Economic Research

ISSN: 2455-8834

Volume:05, Issue:08 "August 2020"

Table 1. The results of the matrix score factors affecting inequality in education

\begin{tabular}{|c|c|c|c|c|c|c|}
\hline & & & Factor & & & \\
\hline & 1 & 2 & 3 & 4 & 5 & 6 \\
\hline X38 & 0,896 & & & & & \\
\hline X40 & 0,896 & & & & & \\
\hline X39 & 0,886 & & & & & \\
\hline X35 & 0,872 & & & & & \\
\hline X36 & 0,854 & & & & & \\
\hline X34 & 0,852 & & & & & \\
\hline X30 & 0,845 & & & & & \\
\hline X37 & 0,843 & & & & & \\
\hline X31 & 0,806 & & & & & \\
\hline X32 & 0,797 & & & & & \\
\hline X33 & 0,782 & & & & & \\
\hline X29 & 0,775 & & & & & \\
\hline $\mathrm{X} 4$ & & 0,943 & & & & \\
\hline $\mathrm{X} 1$ & & 0,931 & & & & \\
\hline $\mathrm{X} 2$ & & 0,913 & & & & \\
\hline X3 & & 0,898 & & & & \\
\hline X5 & & 0,882 & & & & \\
\hline $\mathrm{X} 6$ & & 0,810 & & & & \\
\hline $\mathrm{X} 21$ & & & 0,959 & & & \\
\hline X19 & & & 0,955 & & & \\
\hline $\mathrm{X} 20$ & & & 0,930 & & & \\
\hline $\mathrm{X} 22$ & & & 0,913 & & & \\
\hline X18 & & & 0,693 & & & \\
\hline $\mathrm{X} 25$ & & & & 0,850 & & \\
\hline X26 & & & & 0,844 & & \\
\hline $\mathrm{X} 28$ & & & & 0,751 & & \\
\hline X24 & & & & 0,737 & & \\
\hline $\mathrm{X} 27$ & & & & 0,719 & & \\
\hline $\mathrm{X} 8$ & & & & & 0,884 & \\
\hline X10 & & & & & 0,882 & \\
\hline X7 & & & & & 0,840 & \\
\hline X9 & & & & & 0,792 & \\
\hline$\overline{\mathrm{X} 14}$ & & & & & & 0,812 \\
\hline X16 & & & & & & 0,799 \\
\hline X15 & & & & & & 0,789 \\
\hline
\end{tabular}

(Source: Surveyed by the author, 2020) 


\section{International Journal of Social Science and Economic Research}

ISSN: $2455-8834$

Volume:05, Issue:08 "August 2020"

In the research model, there were 06 independent factors affecting the inequality in education, so the factors will have the following functions:

$\mathrm{B}_{1}=0,119 * \mathrm{X} 40+0,113 * \mathrm{X} 35+0,112 * \mathrm{X} 38+0,111 * \mathrm{X} 36+0,109 * \mathrm{X} 39+0,108 * \mathrm{X} 34+$ $0,107 * \mathrm{X} 37+0,104 * \mathrm{X} 30+0,095 * \mathrm{X} 31+0,095 * \mathrm{X} 32+0,091 * \mathrm{X} 33+0,089 * \mathrm{X} 29$

$\mathrm{B}_{2}=0,201 * \mathrm{X} 1+0,2 * \mathrm{X} 4+0,197 \mathrm{X} 2+0,19 * \mathrm{X} 5+0,189 * \mathrm{X} 3+0,159 * \mathrm{X} 6$

$\mathrm{B}_{3}=0,240 * \mathrm{X} 21+0,239 * \mathrm{X} 19+0,235 * \mathrm{X} 20+0,227 * \mathrm{X} 22+0,174 * \mathrm{X} 18$

$\mathrm{B}_{4}=0,302 * \mathrm{X} 25+0,299 * \mathrm{X} 26+0,252 * \mathrm{X} 28+0,244 * \mathrm{X} 24+0,242 * \mathrm{X} 27$

$\mathrm{B}_{5}=0,337 * \mathrm{X} 10+0,307 * \mathrm{X} 8+0,287 * \mathrm{X} 7+0,262 * \mathrm{X} 9$

$\mathrm{B}_{6}=0,441 * \mathrm{X} 14+0,426 * \mathrm{X} 16+0,418 * \mathrm{X} 15$

The order of the importance of each factor depends on the absolute value of the coefficient that precedes each variable. The bigger the factor of absolute value, the more important the effect is on variable $\mathrm{B}$.

The first group of factors is the local support policy, developing safety plans for students that have the strongest impact on the local support policy with a coefficient of 0.191 . In terms of family conditions, low family income has a strong impact on education equality because it affects the attendance of children and the importance of going to school with a coefficient of 0.201 . The second group of factors is social prejudice, the capacity of thinking and creativity of females and men has the strongest impact on the gender equality with a coefficient of 0.24 , it meant that females are less creative than males. In the school environment factor group, the teachers did not have enough experience to balance the thinking in order to create opportunities for males and females to join classes that have a strong impact on gender equality in education with a coefficient of 0.302 . The group of factors belongs to family orientation, respecting children's decisions has a strong impact on gender equality in education about the children's freedom of career choice with a coefficient of 0.373. Finally, the group of individual factors, their passion has the strongest impact on gender equality in education with a coefficient of 0.441 .

In summary, there are 06-factor groups affecting gender equality in education including local support policies, family conditions, social prejudices, school environment, family orientation and individuals. In which each factor group is determined to have the strongest impact factor. However, the limitation of the study is that it has not yet found a group of factors that have the strongest impact on gender equality in education among these 06 groups of factors.

\subsection{Solutions for gender equality in education at Dai Tam, My Xuyen, Soc Trang}

In order to minimize the situation of inequality in rural education in Dai Tam, My Xuyen district, Soc Trang province, the study proposed some specific solutions as follows: 


\section{International Journal of Social Science and Economic Research}

ISSN: $2455-8834$

Volume:05, Issue:08 "August 2020"

Firstly, to raise people's awareness: (1) Actively closing gender gaps in workplaces, classrooms and schools, it is necessary to raise the awareness of teachers and students about gender equality, and especially change the minds of students, teachers; (2) Social prejudice and language barriers, local people should eliminate prejudices and barriers for both males and females. There is a need to reconsider how education resources are allocated, budget allocations and management responsibilities for upper secondary education; (3) Focusing on scaling up good models to implement gender equality, local authorities need to implement propaganda models on gender equality such as "Gender equality club", working division "Counseling, supporting gender violence", Building the "Shelter houses" to support gender abusers. In particular, (4) promoting the implementation of the provisions of the law, national action programs on gender equality like integrating gender equality works into political tasks of institutions, schools, agencies, socioeconomic development programs of localities; (5) Strictly handle violations and gender discrimination to deter people in society, these cases need to be widely disseminated in various forms, such as holding mobile trials; oral propaganda at residential areas; integrating into local radio and television programs to create the best spillover effect to warn and prevent people from violating.

Second, promoting the implementation of the provisions of the law, national action programs on gender equality

It is necessary to change the current regulations which are not appropriate or make limit gender equality. Especially, the Law on Marriage and Family 2014, in Clause 1, Article 71, clearly stated that "Parents have equal obligations and rights in taking care of and bringing up young children together". But in Clause 4, Article 2, on the basic principle of the implementation of the marriage and family regime, continues to maintain the gender prejudice regulated: "mothershelping to fulfill the noble function of the mother; implement family planning". This rule is no different from assuming that the responsibility of raising children still belongs to the mother, family planning is still the responsibility of the wife. That is to say, it is necessary to adjust inappropriate regulations and to eliminate gender prejudice in the legal documents.

Thirdly, actively narrowing gender gaps in the workplace and all fields

It can be seen that it needs to be orienting and encouraging the implementation of gender equality in all areas of social and family life, including politics, economics, labor, education and training, science and technology, culture and information, sports, healthcare and family. There are no gender preconceptions, no prejudice; Elimination of all gender discrimination, including direct and indirect discrimination. Gender equality in health care: Reforming and developing a health counseling network, especially reproductive health; safe sex and sex education for all ages; encouraging males and females to apply contraceptive measures; propagating and guiding females to know how to take care of themselves and their families; disease prevention, 


\section{International Journal of Social Science and Economic Research}

ISSN: $2455-8834$

Volume:05, Issue:08 "August 2020"

renovating improved policies, social infrastructure so that they have conditions to develop their careers (better kindergarten system, kindergarten ...).

Fourthly, focus on scaling up gender equality implementation models

The localities have implemented and developed models of propaganda on gender equality such as "Gender equality club", working division "counseling, supporting gender violence", building the "Shelter houses" to support the people who are violent. Gender equality in general has a positive effect on the quality of human resources of the future and is of great importance to the country's development. In addition, the implementation of action plans and models on gender equality in education in general and in the education sector at the study site, in particular, is really essential, contributing to the country's renovation and building society as its democracy, progress, justice and civilization.

\section{Conclusions}

Improving the role of women in education is a necessary measure to address gender inequality in education today in Dai Tam, My Xuyen District, Soc Trang Province. The society should not bring gender prejudice as well as create gender prejudice. In which, all gender discrimination need to be eliminated, including direct and indirect discrimination. Currently, the situation of inequality for females and girls in education still exists in today's society, especially in rural areas. The study found that there are many groups of factors affecting gender equality including supportive local policies, family conditions, social prejudices, school environment, family orientation and individuals. Since then, it showed that the causes of inequality in education are closely related to many other issues in society, especially economics and traditional culture as social prejudice, family conditions, schooling environment and individuals. Therefore, policies and models to promote gender equality must focus on gender mainstreaming into social, school and family policies. This has great significance in pushing back the gender inequality, contributing to the development of human and social development.

\section{REFERENCES}

[1] Thu Ha, 2018. Raising awareness of gender equality in education. Vietnam Farmers' Association. http://www.hoinongdan.org.vn/sitepages/news/1145/73415/nang-cao-nhan-thuc-vebinh-dang-gioi-trong-linh-vuc-giao-duc.

[2] The Law on Gender Equality (Vietnam), 2006.

[3] Mac Thi Cam Tu, 2012. Gender equality in education in Ho Chi Minh City - Situation and solutions. Journal of Ho Chi Minh City University of Pedagogy, No. 49 (2013), P59 - 65. 
International Journal of Social Science and Economic Research

ISSN: 2455-8834

Volume:05, Issue:08 "August 2020"

[4] Huu Ngo, 2017. Gender inequality - The main cause of domestic violence. Vietnam Farmers' Association. http: //www.hoinongdan.org.vn/sitepages/news/1145/54853/bat-binh-dang-gioi$\% \mathrm{E} 2 \% 80 \% 93$ nguyen-nhan-chinh-cua-bao-luc -family.

[5] Hoang Ba Thinh, 2008. Sociology textbook on Gender, Hanoi National University Press.

[6] Pham Thi Ly, Phan Van Thang, 2019. Inequality in education in Vietnam. https://www.lypham.net/

[7] UNESCO, 2019. Global Education Monitoring report 2019: Gender report: Building bridges for gender equality, P7 - 9, ISBN:978-92-3-100329-5

[8] PV, 2018. Gender inequality in truth education is not well known. Family and social newspaper. http://giad.NET.vn/giao-duc/bat-binh-dang-gioi-trong-giao-duc-su-that-it-nguoi-biet.

[9] Duong Chi Thien, 2014. Inequality between urban and rural areas in access to education in Vietnam. Journal of Social Science, No. 3 (2014), P73 - 85.

[10] Ly Ngoc Nhan, 2014. Evaluation of gender inequality in Vietnam in recent years (20092012) in the case of Tra Vinh province. Ho Chi Minh City Journal of Social Sciences and Humanities, No. 15 (2014), P40 --7.

[11] Anh Tuan, 2019. Gender inequality - the cause of domestic violence. Vietnam Farmers' Association. http://www.hoinongdan.org.vn/sitepages/news/1145/88481/bat-binh-dang-gioinguyen-nhan-cua-bao-luc-gia-dinh.

[12] Institute for Social Development Studies, 2015. Social factors determining gender inequality in Vietnam. Research results from 2012 to 2015, Hong Duc Publishing House, P34 - 39.

[13] Nguyen Dinh Tho, 2011. Methods of scientific research in business, Social Labor Publishing House, Hanoi, P134 - 153.

[14] Hoang Trong, Chu Nguyen Mong Ngoc, 2008. Analyzing research data with SPSS volumes 1 and 2, Hong Duc Publishing House. 